\title{
Application of Adjacent Categories and Continuation Ratio Logit Models in Determining Factors Influencing Malnutrition in Children Living in the Eastern Part of Freetown, Sierra Leone.
}

\author{
Regina Baby Sesay ${ }^{* 1}$, Sheku Seppeh ${ }^{2}$ \\ ${ }^{1,2}$ Department of Mathematics and Statistics, School of Technology, Njala University, Njala, Sierra Leone
}

\begin{abstract}
Malnutrition in children under five years of age remains a problem in many part of the world especially in Africa of which Sierra Leone is not an exception. In Sierra Leone, the magnitude of stunting, underweight and wasting in children less than five years increases tremendously in the rural areas, especially in the raining season. Child growth is nationally and internationally recognized as a principal indicator of the nutritional and health status of the populations of a country. Therefore, identifying the main factors associated with childhood malnutrition can help to inform and advice both Government and other national health agencies to implement policies that will help to alleviate or minimize the incidence in the country. No research have been conducted especially after the 5 years Sierra Leone rebel war, to particularly investigate the factors influencing malnutrition in under-five children living in this part of the country. This research work, therefore, aimed to identify the main factors influencing malnutrition in under-five children living in the eastern part of the capital city of Sierra Leone. A random sampling method was used to collect 500 observations from the study area. An ordinal logistic regression modelling techniques that involved the proportional odds; the nonproportional odds adjacent categories and the non-proportional odds forward continuation ratio logit models were used in the empirical analysis. Statistical tests showed that, the nonproportional odds adjacent category model outperformed both the proportional odds and the non-proportional odds continuation ratio models. Based on the empirical evidence, the mother's age, the family income level and the number of postnatal hospital visits were the main factors influencing the malnutrition status of the under-five children living the study area. The child's age and the child's feeding status were also found to be significant determinants of under-five children malnutrition status. Malnutrition increases in under-five children from younger mothers, as compared to under-five children from older mothers. The more frequent, the number of post-natal hospital visit, the lower the malnutrition status of the under-five children. Similarly, increase in family income will reduce the incidence of malnutrition in under-five children. Also, malnutrition increases in older children as compared to younger children. Finally, the higher the quality and frequency of child's feed, the lower the incidence of malnutrition in under-five children.
\end{abstract}

Keywords: Ordinal Regression, Sierra Leone, Continuation ratio model, Adjacent category model, Non-proportional odd model, Child malnutrition, Brant test.

\section{INTRODUCTION}

Sierra Leone like any other developing country has been Sexperiencing childhood malnutrition especially after the five years rebel war, during which many urban dwellers migrated to the capital city in search of food and refuge. In Sierra Leone today, under-five children malnutrition is visually prominent in the raining season due to inability of many to afford a well-balanced diet. During this time of the year, the food intake by many under-five children is predominantly carbohydrates. This implies that, the intake of essential food nutrients needed for child growth and immunity boasting are minimal or absolutely absent during this season of the year.

Malnutrition has both the immediate and long lasting effect on the affected children. In the short term, malnutrition (also refer to as nutrient deficiency, imbalance or excess), can negatively affect the immune system thereby making the victim (or malnourished) susceptible to fatal childhood disease. According to the research findings of [9], childhood malnutrition has been identified as a major cause of death among under-five children. Malnutrition also has a negative long lasting impact as it affects health and therefore plays a critical role in the cognitive, social and motor development in the early childhood development. Some researchers in their search for knowledge have unveiled that, poor childhood nutrition is one of the most important conditions that can hinder physical and mental development of children. For example, [18] showed in their research finding that, undernourished children tend to perform worse at school and are less productive in the labor market.

Due to the health threat posed by childhood malnutrition all over Sierra Leone, this research work, tried to identify the main factors influencing malnutrition in under-five children living in the sturdy area. The research considered personal (e.g., Mother's Age), socio-economic (e.g. number of antenatallpostnatal visits and family income) and educational (e.g. mothers educational level)as potential factors that may influence the nutritional status of under-five children living in the sturdy area. 
The age of the mother was considered as the first factor that might influence the nutritional status of under-five children in the sturdy area. This is mainly because young mothers, for example, are less financially powered to guarantee children's timely and adequate dietary intake. Reference [26], also clearly indicated that, the risk of child malnutrition increases with young maternal age.

Also, the mother's educational level was considered as a potential determinant of childhood malnutrition. It is expected that children from well-educated mothers suffer less from malnutrition. A number of research findings have also identified the associated between the educational level of the mother and the nutritional status of children (e.g., [8] and [1]. Research findings have further reported that there is an inverse relationship between maternal education and child malnutrition (e.g., [20] and [8]).

Furthermore, the family income was considered as a potential determinant of childhood malnutrition. In Sierra Leone, childhood, malnutrition has been recognized as a sign and consequence of poverty. Children from low income families may not have access to foods that contain the necessary nutrients that would foster their growth and good health. As a result, these nutritionally deprived children may become less productive to themselves, family and to the countries in which they reside. This is because, malnutrition can hinder the mental capacity of affected individuals, thereby reducing the level of productivity of such individuals, making them less productive and more vulnerable to lack and poverty. It has been documented that higher rates of malnutrition can be found in areas with chronic poverty [3].

Finally, the number of hospital visits made by mothers was also considered as possible determinants of under-five children malnutrition. Because health and malnutrition are inter-related, prenatal and antenatal visits are vital to protect the newborn child from malnutrition and ill health. Expected mothers are therefore, mostly advice to visit the hospital both before and after child bearing. Most vitamin supplements administered to these expected mothers by the hospital can help boast the nutritional status of both the child and the mother.

\section{MATERIALS: THEORETICAL FRAMEWORK}

This section deals with the main theories and concepts used in the empirical analysis

\section{A. Regression models with categorical outcome variables}

Regression models are mostly chosen based on the nature of the dependent variable. In cases where the dependent variable is dichotomous, the binary logistic regression model is the best model to consider, with more than two categories of the dependent variable, with no regards to the order of the categories, a multinomial regression model can be considered. However, with multiple naturally ordered categories of the dependent variable, a regression model (like the ordinal regression) that takes into account the ordering of the categories of the dependent variable would be more appropriate. Therefore, based on the objective of the research and the nature of the categories of the dependent variable, different ordinal regression models were considered. These include, the proportional odds model commonly known as the baseline regression model for ordinal data [19]; the continuation ratio model (forward) that is mostly used in situations where the individual categories of the response variable are of vital interest to the researcher [11] and the Adjacent category models [4] used to incorporate the ordering of the response.

These ordinal models have different forms and analytical methods for constructing their logits. However, these ordinal models share the same stringent model assumption of "proportionality" or "parallel logits". Though essential, but very often, these model assumptions are violated. If the assumption of proportionality is not satisfied by any of these ordinal models, an alternative model that does not impose the assumption of parallel logits should be considered. For each of the ordinal models highlighted above, there exist two alternative models to use in case the proportional odd assumption is somehow violated. The first is the nonproportional odds model. This is achieved by relaxing the parallel line (or proportional odd) assumption for all the independent variables in the model. The second is the partialproportional odd model. This is achieved by relaxing the parallel line (or proportionality) assumption only for some independent variables. For the purpose of this research, three ordinal regression models: the proportional odds; the continuation ratio (or $\mathrm{CR}$ ) and the adjacent category (or AC) models were used in the analysis.

1) Proportional-odds cumulative logit model: This model is mostly referred to as the baseline model for data with an ordinal response outcome. The proportional-odds cumulative logit model uses cumulative probabilities up to a threshold, thereby making the whole range of ordinal categories binary at that threshold.

For $Y=1,2, . . j$ naturally ordered response categories, with associated probabilities,

$$
\begin{array}{r}
\left(\pi_{1}, \pi_{2}, \ldots, \pi_{\mathrm{j}}\right), \text { The cumulative logit is defined as } \\
\log \left(\frac{p(Y \leq j)}{P(Y>j)}\right)=\log \left(\frac{p(Y \leq j)}{1-P(Y \leq j)}\right)=\log \left(\frac{\pi_{1}+\cdots+\pi_{j}}{\pi_{j+1}+\cdots+\pi_{J}}\right)
\end{array}
$$

where the cumulative probability of a response less than equal to $j$ is:

$$
p(Y \leq j)=\pi_{1}+\cdots+\pi_{j}
$$

2)The continuation ratio $(C R)$ model: The baseline model called the proportional odds model focuses on estimating the cumulative probability of being at or below a particular level of the response variable, or being beyond a particular level. . In this research, the ordinal categories represent successive stages of nutritional deficiency through which the child can depreciate. 
Therefore, in a situation where the objective of the research is directed towards a particular category, rather than below that category, given that the subject of investigation must pass through a lower level or category before achieving a higher category, the best choice model is the continuation ratio (CR) model ([10], [13]; [16])

Moreover, the nutritional status of the under five children progresses from the lower stage (slightly malnourished) through to the middle stage (malnourished) and then to the higher stage (highly Malnourished).Therefore, the forward CR model becomes handy in estimating the odds of being in a particular category relative to the odds of being in that category or beyond or the probability of being in a category, given that an individual has been in that category or beyond. For such situation, the CR model can be formulated as [5], [6], [7], [16] follows:

$$
\begin{array}{r}
\operatorname{In}\left(\frac{P\left(Y=j \backslash x_{1}, x_{2}, \ldots x_{p}\right.}{Y \geq j \backslash x_{1}, x_{2}, \ldots x_{p}}\right) \\
=\alpha_{j}+\left(-\beta_{1} X_{1}-\beta_{2} X_{2}-\cdots-\beta_{p} X_{P}\right)
\end{array}
$$

Where $P\left(Y=j \backslash x_{1}, x_{2}, \ldots x_{p}\right)$ is the conditional probability of being in category $\mathrm{j}$ conditioned on being in or above that category given a set of predictors, that is,

$P(Y=j \backslash Y \geq) ; j=1,2, \ldots, j-1$; where the $\alpha_{j}$ are the cutoff points; and $\beta_{1}, \beta_{2}, \ldots, \beta_{p}$ are the logit coefficients.

When estimating the conditional probability of being above a category given that an individual has attained that particular category, that is, $P(Y>j \mid Y \geq j)$ [17], the CR model can be expressed in the following form:

$$
\begin{array}{r}
\operatorname{In}\left(\frac{P\left(Y>j \backslash x_{1}, x_{2}, \ldots x_{p}\right.}{Y=j \backslash x_{1}, x_{2}, \ldots x_{p}}\right) \\
\left.=\alpha_{j}+\beta_{1} X_{1}+\beta_{2} X_{2}+\cdots+\beta_{p} X_{P}\right)
\end{array}
$$

In this research work, since the 'highly malnourished' status of the child is of prime importance to the researcher (as this level can be fetal for the child concern) and a child has to pass through the lower stages or categories of malnutrition before getting to the fetal (or higher) stage, the most appropriate model to consider is the continuation ratio model. In particular, this research work will use the forward CR model, as the research interest is to estimates the odds of being in a particular category say $j$ relative to being above that category.

\section{Logits of the continuation ratio model}

In general, based on the order of the categories of the response variable, the $(\mathrm{J}-1)$ logits for the continuation ratio model are form as follows:

$$
\log \left(\frac{\pi_{1}}{\pi_{2}}\right), \log \left(\frac{\pi_{i}+\pi_{2}}{\pi_{3}}\right), \ldots, \log \left(\frac{\pi_{1}+\cdots,+\pi_{j-1}}{\pi_{j}}\right),
$$

or

$$
\log \left(\frac{\pi_{1}}{\pi_{1}+\cdots,+\pi_{j}}\right), \log \left(\frac{\pi_{2}}{\pi_{1}+\cdots,+\pi_{j}}\right), \ldots, \log \left(\frac{\pi_{j-1}}{\pi_{j}}\right)
$$

Specifically, with respect to the present research, with three response categories, the log odds for the continuation ratio model can take the following forms:

$\ln \left\{\frac{\operatorname{Pr}\left[\left(Y_{i}=y_{1}\right.\right.}{\operatorname{Pr}\left\{\left(Y_{i}>y_{1}\right.\right.}\right\}$, is the log odds based on category 1 relative to being in a category above 1

$\ln \left\{\frac{\operatorname{Pr}\left[\left(Y_{i}=y_{2}\right.\right.}{\operatorname{Pr}\left\{\left(Y_{i}>y_{2}\right.\right.}\right\}$, is the log odds based on category 2 relative to being in a category above 2 .

3) Adjacent category model (ACM): In general, for ordinal regression, the response categories are ordered. To incorporate the ordering of the response, we used the adjacent categories. In the adjacent category modelling, instead of comparing the probability of each category versus a baseline, the probabilities of adjacent categories are considered. For the outcome variable (malnutrition status) used in this research work with categories:

\section{Very Malnourish}

\section{Malnourish}

\section{Moderatly malnourish}

The adjacent category modeling approach considers the probability of:

Very Malnourish versus Malnourish, and Malnourish versus Moderately malnourish,

The model to be estimated for the adjacent category model takes the following form:

$$
\begin{gathered}
\log \left(\frac{\pi_{i j}}{\pi_{i j}}\right)=\left(\alpha_{j}+\beta x_{i}\right)+\left(\alpha_{j}+\beta x_{i}\right)+\cdots+\left(\alpha_{j-1}+\beta x_{i}\right) \\
=\sum_{k=j}^{j-1} \alpha_{k}+\beta(j-1) x_{i}
\end{gathered}
$$

\section{Logits for the adjacent category model}

In ordinal regression analysis, the adjacent categories are easily compared using the adjacent category model. For instance, for the $\mathrm{j}$ categories of the ordinal response variable, the adjacent category model (ACM) works by forming $j-1$ logits for all pairs of adjacent categories. Instead of using all the categories in forming logits, the adjacent category model can just use $J-1$ pairs of the categories. Therefore, with respect to the observed response categories, the logits for the adjacent category model can take the following forms:

$$
\begin{aligned}
& L_{1}=\log \left(\frac{\pi_{1}}{\pi_{2}}\right) \\
& L_{2}=\log \left(\frac{\pi_{2}}{\pi_{3}}\right)
\end{aligned}
$$




$$
L_{2}=\log \left(\frac{\pi_{j-1}}{\pi_{j}}\right)
$$

For this research work, the $\mathrm{j}$ is equal to three (i.e., $\mathrm{j}=3$ ) as there are 3 ordered categories, the probability for the $\mathrm{j}$ ordered outcome with $\mathrm{j}-1$ adjacent pairs can be compared as:

$L_{1}=\log \left[\frac{\operatorname{Pr}\left(Y_{i}=1\right)}{\operatorname{Pr}\left(Y_{i}=2\right)}\right]$ Is the log odds based on the very malnourish versus malnourish

$L_{2}=\log \left[\frac{\operatorname{Pr}\left(Y_{i}=2\right)}{\operatorname{Pr}\left(Y_{i}=3\right)}\right]$ Is the log odds based on the malnourish versus moderately malnourish,

In general, the adjacent category legit model with explanatory variables included can takes the following form:

$\log \frac{(P(Y=j))}{((P(Y=j+1)))}=\hat{\alpha}_{j}+\beta_{1} X_{1}+\beta_{2} X_{2}+\beta_{3} X_{3}+\ldots j=1, \ldots, J$

\section{METHODOLOGY}

\section{A. Choice of the Dependent Variable}

The malnutrition status of the child was used as the dependent variable. The occurrence and severity of malnutrition in children normally proceeds in stages (e.g., from less severe to a more severe stage). The dependent variable was, therefore, naturally ordered following these stages. Arranged in descending order of magnitude (i.e. from highly malnourished to moderately malnourished), the outcome variable, child malnutrition status was categorized as follows:

1= Very Malnourish, 2 Malnourish, 3= Moderatly malnourish, with very malnourish as the highest category of child malnutrition status.

That is:

$\mathrm{Y}=$ child malnutrition level

$=\left\{\begin{array}{cc}1 & \text { Very malnourish } \\ 2 & \text { malnourish } \\ 3 & \text { Moderately malnourish }\end{array}\right.$

1) Measurement of the Dependent Variable: With reference to [26], the three anthropometric indices that involve the $\mathrm{z}$-score of height-for-age (stunting); weight-for-height (wasting) and weight-for-age (underweight) were used in the measurement of the dependent variable. Based on [27], for child growth standards, the three anthropometric indices were constructed as: height-for-age with $\mathrm{Z}$ score less than -2 standard deviations [SDs] (stunting); weight-for-age with $\mathrm{z}$ score less than -2 SDs (underweight); and weight-for-height with $\mathrm{z}$ score less than -2 SDs (wasting).

These measurements helped to determine the level (or extent) of malnutrition associated with each under-five child living in the study area. With regards to measurement based on these three anthropometric indices, the malnutrition status of each child was classified as: 'highly malnourish' (extremely stunted, wasted or obesed), 'Malnourish' (stunted, wasted or obesed) and 'slightly malnourish' (slightly stunted, wasted or obesed).

2) Independent Variables: The independent variables used in this research are: Mothers Age, Mother's educational status, Family income, Family size, Child's Age, Child's Feed, and postnatal hospital visits

\section{EMPIRICAL ANALYSIS}

This analysis aimed at identifying the significant determinant of the malnutrition status of the under-five children living in the sturdy area. First, the descriptive and exploratory analysis

\section{A. Descriptive and Exploratory Data Analysis}

Table I presents the summary description of the dependent and Independent variables used in the analysis

\begin{tabular}{|c|c|c|c|}
\hline $\begin{array}{l}\text { Variable } \\
\text { Name }\end{array}$ & $\begin{array}{c}\text { IV/ } \\
\text { D } \\
\text { V }\end{array}$ & Valid Range & Variable Type \\
\hline $\begin{array}{c}\text { Child } \\
\text { Manutrition } \\
\text { Status } \\
\text { (level) }\end{array}$ & DV & $\begin{array}{l}\text { highly malnourish } \\
\text { malnourish } \\
\text { Moderaqtely malnouris }\end{array}$ & Categorical \\
\hline $\begin{array}{l}\text { Mothers } \\
\text { Age }\end{array}$ & IV & $\begin{array}{l}\leq 20 \text { years } \\
\leq 30 \text { years } \\
>40 \text { years }\end{array}$ & Categorical \\
\hline $\begin{array}{l}\text { Mother's } \\
\text { Educational } \\
\text { Level }\end{array}$ & IV & $\begin{array}{l}\text { No Formal Education } \\
\text { Primary Education } \\
\text { Secondary Education } \\
\text { Tertiary Education }\end{array}$ & Categorical \\
\hline $\begin{array}{c}\text { Family } \\
\text { IncomeLeve } \\
1\end{array}$ & IV & $\begin{array}{l}\text { Low } \\
\text { Medium } \\
\text { High }\end{array}$ & Categorical \\
\hline $\begin{array}{l}\text { Birth } \\
\text { interval }\end{array}$ & IV & $\begin{array}{l}\text { less than } 12 \text { months } \\
12-23 \text { months } \\
24-35 \text { months } \\
36 \text { months and above }\end{array}$ & Categorical \\
\hline Family Size & & $\begin{array}{l}\text { <3-small, =3-normal, } \\
>3 \text {-big }\end{array}$ & Continuous \\
\hline $\begin{array}{l}\text { Child's } \\
\text { Birth weight }\end{array}$ & IV & $\begin{array}{l}\text { Low birth weight= less } \\
\text { than } 5 \text { pounds, } 8 \text { ounces } \\
(2,500 \text { grams). } \\
\text { very low birth weight.= } \\
\text { less than } 3 \text { pounds, } 5 \\
\text { ounces }(1,500 \text { grams }) \\
\text { nomal birth weight= } \\
\text { was around } 7.5 \mathrm{lb}(3.5 \\
\mathrm{kg}), 5.5 \mathrm{lb}(2.5 \mathrm{~kg}) \text { and } \\
10 \mathrm{lb}(4.5 \mathrm{~kg})\end{array}$ & Categorical \\
\hline $\begin{array}{c}\text { Hospital } \\
\text { Type }\end{array}$ & & $\begin{array}{l}\text { Private } \\
\text { public }\end{array}$ & $\begin{array}{c}\text { Categorical } \\
\text { (Dichotomous) }\end{array}$ \\
\hline Child's Age & IV & $\begin{array}{l}<1 \text { year, } \\
1 \text { to } 2 \text { years } \\
>2 \text { years } \leq 5 \text { years, }\end{array}$ & Categorical \\
\hline Child's Feed & IV & $\begin{array}{l}\text { Low }<3 \\
\text { Medium } \leq 3 \\
\text { High }>3 \text { times }\end{array}$ & Categorical \\
\hline $\begin{array}{l}\text { Pre-natal } \\
\text { Hospital } \\
\text { visit }\end{array}$ & IV & $\begin{array}{l}\text { Regular=always meets } \\
\text { Doctor's appointment } \\
\text { Not regular= Never or } \\
\text { not always }\end{array}$ & $\begin{array}{c}\text { Categorical } \\
\text { (Dichotomous) }\end{array}$ \\
\hline
\end{tabular}

Table I: Dependent (Dv) And Independent (Iv) Variables To Be Modeled 


\begin{tabular}{|c|c|l|c|}
\hline $\begin{array}{c}\text { Post-natal } \\
\text { Hospital } \\
\text { visit }\end{array}$ & IV & $\begin{array}{l}\text { Regular=always meet } \\
\text { Doctors appointment } \\
\text { Not regular= Never or } \\
\text { not always }\end{array}$ & $\begin{array}{c}\text { Categorical } \\
\text { (Dichotomous) }\end{array}$ \\
\hline
\end{tabular}

$>$ Distribution of the levels of under-five children Malnutrition Status :

The bar plot presented in fig 1 displays the level of the malnutrition status for each ordered category of the dependent variable (child's malnutrition status). From fig I, it is clear that, the highly malnourish category bar is higher than the bars in all the other categories. It is therefore worth identifying the main determinants of such alarming number of highly malnourish under-five children living in this part of the country. This information can be used to help the Government and other volunteering organizations to put measures in place that can improve the nutritional status of the children in this part of the country

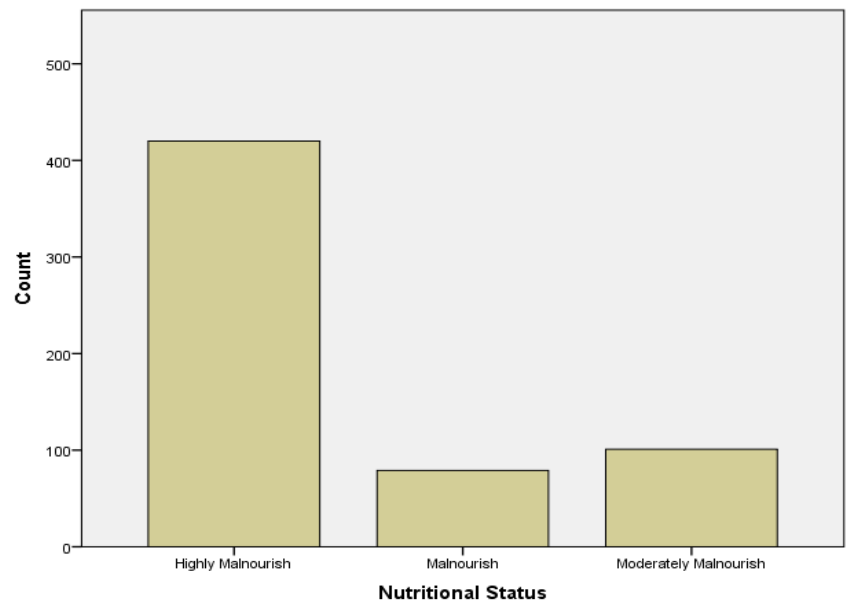

Fig1: Bar plot of Levels of the Outcome Variable

Table II presents the case processing summary result of the categorical variables. From Table II, the marginal percentage of the highly malnourish category of under-five children malnutrition is higher than the other two categories. This shows that under-five children that are highly malnourished are in greater proportion (or number) as compared to those that are just malnourished or moderately malnourished.

Table II: Case Processing Summary

\begin{tabular}{|l|l|c|c|}
\hline \multicolumn{2}{|l|}{} & N & $\begin{array}{c}\text { Marginal } \\
\text { Percenta } \\
\text { ge }\end{array}$ \\
\hline Child & highly malnourish & 347 & $69.4 \%$ \\
Manutritio & malnourish & 73 & $14.6 \%$ \\
Status & Moderately malnourish & 80 & $16.0 \%$ \\
\hline Mother's & No Formal Education & 99 & $19.8 \%$ \\
Educational & Primary Education & 75 & $15.0 \%$ \\
Level & Secondary Education & 222 & $44.4 \&$ \\
& Tertiary Education & 104 & $20.8 \%$ \\
\hline Family & Low & 177 & $34.4 \%$ \\
IncomeLeve & Medium & 288 & $57.6 \%$ \\
& High & 35 & $7.0 \%$ \\
\hline
\end{tabular}

\begin{tabular}{|c|c|c|c|}
\hline Family Size & $\begin{array}{l}\text { small, } \\
\text { medium } \\
\text { large }\end{array}$ & $\begin{array}{c}336 \\
93 \\
71 \\
\end{array}$ & $\begin{array}{l}67.2 \% \\
18.6 \% \\
14.2 \%\end{array}$ \\
\hline \multirow{3}{*}{$\begin{array}{l}\text { Child's } \\
\text { Feeding } \\
\text { status }\end{array}$} & Low & 297 & $59.4 \%$ \\
\hline & Medium & 178 & $35.6 \%$ \\
\hline & High & 25 & $5.0 \%$ \\
\hline \multirow{3}{*}{$\begin{array}{l}\text { Child's } \\
\text { Birth } \\
\text { weight }\end{array}$} & Low birth weight & 34 & $6.8 \%$ \\
\hline & very low birth weight & 113 & $22.6 \%$ \\
\hline & nomal birth weight & 363 & $70.6 \%$ \\
\hline \multirow{2}{*}{$\begin{array}{l}\text { Mother's } \\
\text { Occupation }\end{array}$} & Unemployed & 274 & $54.8 \%$ \\
\hline & Employed & 226 & $45.2 \%$ \\
\hline \multirow{2}{*}{$\begin{array}{l}\text { Type of } \\
\text { Hospital }\end{array}$} & Public & 328 & 65.6 \\
\hline & Private & 165 & 33.0 \\
\hline \multirow{2}{*}{$\begin{array}{l}\text { Post-natal } \\
\text { Hospital } \\
\text { visit }\end{array}$} & Regular & 374 & $69.4 \%$ \\
\hline & Not regular & 153 & $30.6 \%$ \\
\hline \multirow{2}{*}{$\begin{array}{l}\text { Pre-natal } \\
\text { Hospital } \\
\text { visit }\end{array}$} & Regular & 328 & $65.6 \%$ \\
\hline & Not regular & 172 & $34.4 \%$ \\
\hline \multirow{3}{*}{$\begin{array}{l}\text { Child's } \\
\text { Age }\end{array}$} & $<1$ year, & 199 & $39.8 \%$ \\
\hline & 1 to 2 years & 198 & $39.6 \%$ \\
\hline & $>2$ year $\leq 5$ years & 103 & $20.6 \%$ \\
\hline \multirow{3}{*}{$\begin{array}{l}\text { Mother's } \\
\text { Age }\end{array}$} & $\leq 20$ years & 80 & $16.0 \%$ \\
\hline & $\leq 30$ years & 252 & $50.4 \%$ \\
\hline & $>40$ years & 168 & $33.6 \%$ \\
\hline
\end{tabular}

Table III presents the chi-square test of independence The Chi-square test of independence presented in Table III was used in the analysis to test whether there was a statistically significant relationship between each categorical independent variable and the categorical ordinal dependent variable. The test works by comparing the observed frequencies to the expected frequencies.

The null hypothesis of the Chi-square test is that, there is no relationship between the two categorical variables. That is, the two categorical variables are independent. On the other hand, the alternative hypothesis is that, the variables are dependent. This implies that, there is a relationship between the two categorical variables.

From the output presented in Table III, the p-values of Child Malnutrition Status paired with each of the independent variables, birth interval, mother's occupation, type of hospital, anti-natal hospital visits and ,child's birth weight were each greater than the chosen significant value of $5 \%$.. This shows that, each of the stated independent variables were not significantly dependent on (or associated with) the outcome variable. In order words, the stated variables were each independent of the outcome variable and were, therefore, dropped from the model. Variables that showed significant association with the dependent variable were used in the ordinal regression modelling.

Table III: Chi-Square Tests of Independence

\begin{tabular}{|c|c|c|c|l|}
\hline Factor & $\begin{array}{c}\text { Pearson } \\
\chi 2\end{array}$ & Value & P -value & Decision \\
\hline $\begin{array}{c}\text { Chi_Manu and } \\
\text { Fam_icom }\end{array}$ & 11.92 & 4 & 0.01796 & $\begin{array}{l}\text { Child Malnutrition } \\
\text { Status is dependent on } \\
\text { the Family income }\end{array}$ \\
\hline $\begin{array}{c}\text { Chi_Manu,dat\$ } \\
\text { Mom_Age }\end{array}$ & 25.561 & 4 & $\begin{array}{c}3.879 \mathrm{e}- \\
05\end{array}$ & $\begin{array}{l}\text { Child Malnutrition } \\
\text { Status is dependent on } \\
\text { the mother's age }\end{array}$ \\
\hline
\end{tabular}




\begin{tabular}{|c|c|c|c|c|}
\hline $\begin{array}{l}\text { Chi_Manu and } \\
\text { dat\$Birth_Inte }\end{array}$ & 5.1296 & 4 & 0.2743 & $\begin{array}{l}\text { Child malnutrition } \\
\text { Status is independent of } \\
\text { the birth interval }\end{array}$ \\
\hline $\begin{array}{l}\text { Chi_Manu and } \\
\text { Chi_Fed }\end{array}$ & 10.628 & 4 & 0.03108 & $\begin{array}{l}\text { Child malnutrition } \\
\text { Status is dependent on } \\
\text { the child's feed }\end{array}$ \\
\hline $\begin{array}{c}\text { Chi_ManuMo } \\
\text { m_Ocu }\end{array}$ & 2.9871 & 2 & 0.2246 & $\begin{array}{l}\text { Child malnutrition } \\
\text { Status is independent } \\
\text { of } \\
\text { the mother's occupation }\end{array}$ \\
\hline $\begin{array}{l}\text { Chi_Manu and } \\
\text { Mom_Edu }\end{array}$ & 24.534 & 6 & $\begin{array}{c}0.00041 \\
63\end{array}$ & $\begin{array}{l}\text { Child malnutrition } \\
\text { Status is dependent on } \\
\text { the mother's education }\end{array}$ \\
\hline $\begin{array}{l}\text { Chi_Manu and } \\
\text { Type_Hos }\end{array}$ & 2.7681 & 2 & 0.2417 & $\begin{array}{l}\text { Child malnutrition } \\
\text { Status is independent of } \\
\text { the type of hospital }\end{array}$ \\
\hline $\begin{array}{l}\text { Manu and } \\
\text { Num_Post }\end{array}$ & 9.5355 & 2 & $\begin{array}{c}0.00849 \\
9\end{array}$ & $\begin{array}{l}\text { Child malnutrition } \\
\text { Status is dependent on } \\
\text { the post-natal hospital } \\
\text { visits }\end{array}$ \\
\hline $\begin{array}{l}\text { Chi_Manu and } \\
\text { Num_Anti }\end{array}$ & 2.8281 & 2 & 0.2432 & $\begin{array}{l}\text { Child malnutrition } \\
\text { Status is independent of } \\
\text { the } \\
\text { Number of anti-natal } \\
\text { hospital visits }\end{array}$ \\
\hline $\begin{array}{l}\text { Chi_Manu and } \\
\text { child's Age }\end{array}$ & 6.3374 & 4 & 0.04206 & $\begin{array}{l}\text { Child malnutrition } \\
\text { Status is dependent on } \\
\text { the child's Age }\end{array}$ \\
\hline $\begin{array}{c}\text { Chi_Manu and } \\
\text { Bweight }\end{array}$ & 2.1281 & 4 & 0.2012 & $\begin{array}{l}\text { Child malnutrition } \\
\text { Status is independent of } \\
\text { the child's birth weight }\end{array}$ \\
\hline
\end{tabular}

\section{B. The Ordinal Logistic Regression Analysis}

1) Analy1sis of the Proportional odd Model: As a baseline ordinal regression model, the proportional odd model is the first model to consider in an ordinal regression analysis. The proportional odd model models the dependence of an ordinal response on discrete or continuous covariates. This model is only good when the effects of the explanatory variables are consistent or proportional across the different ordered categories

From the model estimates provided in Table IV, it can be seen that, the p-values for each of the independent variables, Mothers age, family income, and number of postnatal visits are each less than the chosen significant level of 0.05 . This implies that, based on the proportional odd model, each of these variables are significantly contributing to the under-five children's malnutrition status.

Table IV: Proportional Odd Model Estimates

\begin{tabular}{|c|c|c|c|c|}
\hline & Value & Std. Error & $\mathrm{t}$ value & $\mathrm{p}$ value \\
\hline Mom_Age & 0.55108359 & 0.22301398 & 2.4710720 & 0.01 \\
\hline Mom_Edu & -0.05746599 & 0.14867624 & 0.3865177 & 0.70 \\
\hline Fam_icom & 0.68204972 & 0.27556284 & 2.4751150 & 0.01 \\
\hline Fam_size & 0.20887003 & 0.20368231 & 1.0254697 & 0.31 \\
\hline Chi_Age & 0.42178697 & 0.26642290 & 1.5831483 & 0.11 \\
\hline Chi_Bhealth & 0.03603456 & 0.19100692 & 0.1886558 & 0.85 \\
\hline Chi_Fed & 0.14814569 & 0.23072722 & 0.6420815 & 0.52 \\
\hline Num_Post & 1.02187438 & 0.38428562 & 2.6591533 & 0.01 \\
\hline
\end{tabular}

\begin{tabular}{|l|l|l|l|l|}
\hline $1 \mid 2$ & 1.58883025 & 0.91535440 & 1.7357542 & 0.08 \\
\hline $2 \mid 3$ & 2.73616720 & 0.92316525 & 2.9638975 & 0.00 \\
\hline
\end{tabular}

2) Model Checking:

\section{- Chi-square goodness of fit test for model coefficients}

The model fitting information test presented in Table $\mathrm{V}$ was used to check if the present (Final) model with explanatory variables included is an improvement over the baseline model (intercept only).

A significantly reduced value of the Log- likelihoods (-2LLs) suggests that the new model is explaining more of the variation in the outcome variable than the baseline (or constant only) model. From Table $\mathbf{V}$, the chi-square statistic is highly significant (chi- square $=84.131 \mathrm{df}=15$, pvalue $=0.000$ ), which indicated that the model provided a better fit than the null model.

Table V Model Fitting Information

\begin{tabular}{|c|c|c|c|c|}
\hline Model & $\begin{array}{c}-2 \text { Log } \\
\text { Likelihood }\end{array}$ & $\begin{array}{c}\text { Chi- } \\
\text { Square }\end{array}$ & $\begin{array}{c}\text { d } \\
\text { f }\end{array}$ & Sig. \\
\hline $\begin{array}{c}\text { Intercept } \\
\text { Only }\end{array}$ & 780.805 & & & \\
\hline Final & 696.674 & 84.131 & $\begin{array}{r}1 \\
5\end{array}$ & .000 \\
\hline
\end{tabular}

From the pseudo r-square statistics presented in Table VI, the pseudo $\mathrm{R}^{2}$ values (e.g.Negelkerke. $=0.741=74 \%$ ) indicate that the ordinal logistic regression model with its independent variables explained relatively a good proportion of the variability in the under-five children malnutrition status.

Table VI: Pseudo R-Square Statistics

\begin{tabular}{|c|c|}
\hline \multicolumn{2}{|c|}{ Pseudo R-Squqre } \\
\hline Cox and Snell & .674 \\
Negelkerke & .741 \\
McFadden & .495 \\
\hline Link Function & Logit \\
\hline
\end{tabular}

- Test for Proportionality in the proportional odd model:

The proportional odd assumption is that, the effects of each explanatory variable is consistent (or proportional) across the different ordered categories of the response variable. In this research, the brant test was used to test the proportionality assumption to see whether the observed deviations from the fitted ordinal logistic regression model were larger than what could be attributed to chance alone. The null hypothesis for the brant test is that the parallel assumption holds. Therefore, the parallel (or proportional odd) assumption only holds for variables with $\mathrm{p}$-values greater than the chosen significant value of 0.05 . The brant test for proportionality tests for both the individual variables and for the whole model. Contained in the brant test output is the omnibus variable that stands as a test statistic to test for the whole model. From the output presented in Table VII, the parallel (or proportional odd assumption) does not hold for the full model as the $\mathrm{p}$-value for 
the omnibus variable is less than the chosen significant value of 0.05. Also, the P-value for most of the independent variables were each less than the chosen significant value of 0.05. This rendered the proportional odd ordinal logistic regression model unfit to be used as a final model in the analysis. For this purpose, the adjacent categories logit model with non-proportional odds and the forward continuation ratio models both of which does not depend on the proportional odd assumption were used in the analysis.

Table VII: Brant Test For Proportional Odd Assumption

\begin{tabular}{|c|c|c|c|}
\hline Test for & $\mathrm{X} 2$ & Df & probability \\
\hline Omnibus & 107.76 & 13 & 0 \\
\hline Mom_Age & 6.17 & 1 & 0.01 \\
\hline Fam_icom & 3.68 & 1 & 0.03 \\
\hline Fam_size & 7.29 & 1 & 0.01 \\
\hline Chi_Age & 10.44 & 1 & 0 \\
\hline Chi_Bhealth & 2.19 & 1 & 0.14 \\
\hline Chi_Fed & 6.71 & 1 & 0.01 \\
\hline Num_Post & 0.64 & 1 & 0.42 \\
\hline \multicolumn{4}{|c|}{ H0: Parallel Regression Assumption holds } \\
\hline Test for & $\mathrm{X} 2$ & Df & probability \\
\hline Omnibus & 107.7597290 & 13 & $5.124892 \mathrm{e}-17$ \\
\hline Mom_Age & 6.1672844 & 1 & $1.301342 \mathrm{e}-02$ \\
\hline Mom_Edu & 4.4895782 & 1 & $3.410209 \mathrm{e}-02$ \\
\hline Fam_icom & 3.6766111 & & $5.518090 \mathrm{e}-02$ \\
\hline Fam_size & 7.2933135 & 1 & $1.233346 \mathrm{e}-03$ \\
\hline Chi_Age & 10.4397102 & 1 & $1.233346 \mathrm{e}-03$ \\
\hline Chi_Bhealth & 2.1884242 & 1 & $1.390515 \mathrm{e}-01$ \\
\hline Chi_Fed & 6.7135714 & 1 & $9.568191 \mathrm{e}-03$ \\
\hline Num_Post & 0.6394293 & 1 & $4.239175 \mathrm{e}-01$ \\
\hline
\end{tabular}

\section{Analysis of the Non-proportional Odds Models}

Due to the violation of the proportional odd (or the parallel line) assumption of the baseline model, called the proportional odd model, two non-proportional odd models, the adjacent categories logit and the forward continuation ratio models were used in the analysis.

1)Analysis of the Non-proportional Odds Adjacent Categories Logit Model: The adjacent category logit models are ordinal regression models that concern themselves with the comparisons of adjacent categories. The adjacent category model was used in this research work because the response categories, (the level of malnutrition in under-five children) are of particular interest to the researchers.

The parameter estimates of the non-proportional odds adjacent category model together with standard errors and the corresponding p-values are presented in Table VIII. From Table VIII, the age of the mother was found to be a significant determinant of under-five children malnutrition status. The estimated coefficient associated with mothers age for mothers less than 30 years (younger mothers) is positive (1.1874) and significant ( $\mathrm{p}$-value $=0.000282 * * *<0.05)$. This means that, holding all the other variables constant. The younger the mother, the more severe the malnutrition status of the under five children. In terms of odd ratios, the estimated odds of the under-five children being highly malnourished (versus malnourished or moderately malnourished) for the category of mothers age less than 30 years ( or younger mothers) increase by $\exp (1.1874)=3.2785$ times the odd for the category of mothers' age greater than 30 years ( $\geq 30$ years).

Also, given the educational level of the mother, the estimated coefficient associated with the category of low level of mother's education (e.g., non-formal or primary levels) is positive (0.5002) and significant (p-value=0.027946< 0.05). This means that, compared to mothers with higher (tertiary or secondary) levels of education, holding all the other variables constant. mothers with low level education (non-formal or primary levels ) are associated with higher level of under-five children's malnutrition. In terms of odd ratios, the odds of the under-five children being very malnourish versus malnourish or moderately malnourish for the category of less educated (non-formal or primary) mothers increase by $\exp (0.5002)=1.649$ times the odds for educated or highly educated mothers.

Whereas, the estimated coefficient associated with secondary or tertiary levels (high level) of education is negative (0.4827). This means that, holding all the other variables constant, the higher the level of the mothers' education, the lower the malnutrition status of the under five children. In terms of odd ratios, the estimated odds of the under-five children being very malnourish versus malnourish or moderately malnourish for the category of highly educated (or educated) mothers decrease by $\exp (-0.4827)=0.617$ times the odd for the category of non-educated (or low educated) mothers.

Another significant independent variable is the family income level, the estimated coefficient associated with low level family income is positive and significant (pvalue $=0.027946<0.05$ ). This means that, holding all the other variables constant, low income category of family income can lead to an increase in the malnutrition status of the under-five children. In terms of odd ratios, the odds of the under-five children being very malnourish versus malnourish or moderately malnourish for the category of low level income families increase by $\exp (0.1273)=1.1357$ times the odds for middle or high level income families.

Similarly, given the family income level, the estimated coefficient associated with high level family income is negative and significant ( $\mathrm{p}$-value $=0.005754 * *$ ). This means that, holding all the other variables constant, high level income category of family income can lead to a decrease in the malnutrition status of the under-five children. In terms of odds ratios, the odds of the under-five children being very 
malnourish versus malnourish or moderately malnourish for the category of high (or middle) level income families decrease by $\exp (-1.0580)=$ times the odds for the category of low level income families.

Also, the independent variable category, small family size is a significant contributor to under-five children malnutrition. The estimated coefficient associated with small family size is negative. This means that, holding all the other variables constant, the small family size category of under-five children malnutrition can lead to a decrease in the malnutrition status of the under-five children. In terms of odd ratios, the odds of the under-five children being very malnourish versus malnourish or moderately malnourish for small (or normal) family size decrease by $\exp (-0.8852)$ $=0.41263$ times the odds for the category of large family size.

The age of the child is another significant factor that may influence the under-five children malnutrition status. The estimated coefficient associated with the age of the child is positive (1.1793). This means that, holding all the other variables constant, increase in child's age will lead to an increase in the malnutrition status of the under-five children. In terms of odd ratios, the odds of the under-five children being very malnourish versus malnourish or moderately malnourish for older children increase by $\exp (1.1793)$ $=3.2520$ times the odds for the category of younger children.

The child feeding status (Chi_Fed:1) was also found to be a significant determinant of the under-five children malnutrition status. The estimated coefficient associated with the child feeding status is negative. This means that, holding all the other variables constant, the higher the feeding status (in terms of quality and frequency), the lower the malnutrition status of the under-five children

In terms of odd ratios, the odds of the under-five children being very malnourish versus malnourish or moderately malnourish for high feeding status decrease by $\exp (-1.2019)$ $=0.3006$ times the odds for the category of under-five children with low feeding status.

Finally, the number of postnatal hospital visits was found to be a significant determinant of under-five children malnutrition status, the estimated coefficient associated with a low post-natal hospital visit (not regular visit or never visited the hospital) is positive. This means that, holding all the other variables constant. low post-natal hospital visit category is associated with high level of malnutrition status. In terms of odds ratios, the odds of low post-natal hospital visit increase the malnutrition status by $\exp (1.5743)=4.827$ times the estimated odd of the high category of postnatal hospital visit.

Table VIII Parameter Estimates Of The Adjacent Categories Logit Model With Non-Proportional Odds

\begin{tabular}{|c|c|c|c|c|}
\hline & Estimate & $\begin{array}{c}\text { Std. } \\
\text { Error }\end{array}$ & $\begin{array}{c}\mathrm{z} \\
\text { value }\end{array}$ & $\operatorname{Pr}(>|\mathrm{z}|)$ \\
\hline $\begin{array}{c}\text { (Interce } \\
\text { pt): } 1\end{array}$ & -0.3410 & 1.4694 & -0.232 & 0.816510 \\
\hline (Interce & 3.2536 & 1.3830 & 2.353 & $0.018645 *$ \\
\hline
\end{tabular}

\begin{tabular}{|c|c|c|c|c|}
\hline pt):2 & & & \\
\hline $\begin{array}{c}\text { Mom_- } \\
\text { Age: } 1\end{array}$ & 1.1874 & 0.3270 & -3.631 & $0.000282 * * *$ \\
\hline $\begin{array}{c}\text { Mom_- } \\
\text { Age:2 }\end{array}$ & 0.3697 & 0.3316 & 1.115 & 0.265001 \\
\hline $\begin{array}{c}\text { Mom_- } \\
\text { Edu:1 }\end{array}$ & 0.5002 & 0.2275 & 2.198 & $0.027946 *$ \\
\hline $\begin{array}{c}\text { Mom_- } \\
\text { Edu:2 }\end{array}$ & -0.4827 & 0.2142 & -2.254 & $0.024185 *$ \\
\hline $\begin{array}{c}\text { Fam_ic } \\
\text { om:1 }\end{array}$ & 0.1273 & 0.4045 & 0.315 & 0.753026 \\
\hline $\begin{array}{c}\text { Fam_ic } \\
\text { om:2 }\end{array}$ & -1.0580 & 0.3206 & -2.761 & $0.005754 * *$ \\
\hline $\begin{array}{c}\text { Fam_si } \\
\text { ze:1 }\end{array}$ & -0.8852 & 0.3206 & -2.761 & $0.005754 * *$ \\
\hline $\begin{array}{c}\text { Fam_si } \\
\text { ze:2 }\end{array}$ & 0.5514 & 0.3172 & 1.738 & 0.082127 \\
\hline $\begin{array}{c}\text { Chi_Ag } \\
\text { e:1 }\end{array}$ & 1.1793 & 0.4254 & -3.472 & $0.000516 * * *$ \\
\hline $\begin{array}{c}\text { Chi_Bh } \\
\text { ealth:1 }\end{array}$ & -0.5364 & 0.2918 & -1.838 & 0.066064 \\
\hline $\begin{array}{c}\text { Chi_Bh } \\
\text { ealth:2 }\end{array}$ & 0.3441 & 0.2972 & 1.158 & 0.246840 \\
\hline $\begin{array}{c}\text { Chi_Fe } \\
\text { d:1 }\end{array}$ & -1.2019 & 0.3999 & -3.006 & $0.002648 * *$ \\
\hline $\begin{array}{c}\text { Chi_Fe } \\
\text { d:2 }\end{array}$ & 0.5554 & 0.3128 & 1.775 & 0.075833 \\
\hline $\begin{array}{c}\text { Num_P } \\
\text { ost:1 }\end{array}$ & 0.1572 & 0.6354 & 0.247 & 0.804639 \\
\hline $\begin{array}{c}\text { Num_P } \\
\text { ost:2 }\end{array}$ & 1.5743 & 0.5946 & 2.648 & $0.008108 * *$ \\
\hline
\end{tabular}

2) Analysis of the Forward Continuation Ratio (CR) Logit Models with Non-proportional Odds: The continuation ratio model with non-propotional odd relaxes the assumption of proportional odds for all independent variables (or covariates) in the model.

The forward CR model estimates the odds of being above (or beyond) a particular category relative to being in that category, which are the exponentiated logit coefficient $\exp (\beta)$ for a one-unit change in a predictor.

In this research work, a forward CR model with eight predictors was used in the analysis to estimate the odds of the under-five children being above a particular malnutrition category relative to being in that category. Table IX presents the estimated forward CR model coefficients, standard errors, together with their corresponding p-values and odd ratios.

All independent variables with positive coefficient and corresponding odd ratios greater than one implies that a unit increase in the independent variable will lead to shift from a lower category (very malnourished) to a higher category (malnourished or moderately malnourished). Amongst the independent variables used in the model, four of the coefficients of the seven predictor variables on child malnutrition status were significant.

The estimated logit coefficient for mothers age (Mom Age) is, $\beta=0.38822$ with $p=0.04412<0.05$, this implies that increase in mothers age will shift the malnutrition status from the highly malnourished category (i.e. lower category 1 ) to a category beyond, i.e., the malnourished or moderately 
malnourished category (category 2 or 3 ). This means that increase in the age of the mother will lead to an increase or improvement in the nutritional status of the under-five children (i.e., from highly malnourished to malnourished or moderately malnourished), In terms of odds ratios (OR), the odds of being beyond a particular malnutrition status increased by a factor of 1.4744 with a one-unit increase in mothers age (i.e. eg. From $1=$ highly malnourished to $2=$ malnourished or $3=$ moderately malnourished).

Similarly, the logit coefficient for family income (Fam_icom) is $\beta=0.62388$ with $p=0.00736<0.05$. This implies that increase in family income will shift the malnutrition status from lower category. That is, from the highly malnourished category (i.e. lower category 1 ) to a category beyond, i.e., the malnourished or moderately malnourished category (category 2 or 3). This means that increase in family income will lead to an increase or improvement in the nutritional status of the under-five children. In terms of odds ratios (OR), the odds of being above a particular malnutrition category increase by a factor 1.866 for a one unit increase in family income.

Also, the logit coefficient for child's Age (Chi Age) is $\beta$ $=0.49275$ with $p=0.03584<0.05$. This implies that increase in child's Age will shift the malnutrition status from lower category ( 1 =highly malnourished) to a higher category ( $2=$ malnourished or moderately malnourished).This means that increase in child's Age will lead to an increase or improvement in the nutritional status of the under-five children. In terms of odds ratios (OR), the odds of being above a particular malnutrition category increase by a factor 1.6368148 for a one unit increase in child's Age.

Again, the logit coefficient for number of post-natal visits (Num_post) is $\beta=0.99439$ with $p=0.00338<0.05$. This implies that increase in post-natal visits will shift the malnutrition status from lower category, that is from highly malnourished (1=highly malnourished) to a higher category $(2=$ malnourished or moderately malnourished). This means that increase in post-natal visits will lead to an increase or improvement in the nutritional status of the under-five children. In terms of odds ratios (OR), the odds of being above a particular malnutrition category increase by a factor 2.70307 for a one unit increase in the number of post-natal visits.

However, the independent variables, mother's educational status (Mom_Edu); family size (Fam_size); child's birth health (Chi_Bhealth) and child's feeding frequency are not significantly contributing to the under-five children malnutrition status as the p-values for each of these factors is greater than the chosen significant value of 0.05 .

Table IX: Coefficient Estimates Of The Forward Continuation Ratio Model

\begin{tabular}{|c|c|c|c|l|l|}
\hline & $\begin{array}{c}\text { Estima } \\
\text { te }\end{array}$ & $\begin{array}{c}\text { Std. } \\
\text { Error }\end{array}$ & $\begin{array}{c}\mathbf{z} \\
\text { valu } \\
\mathbf{e}\end{array}$ & $\operatorname{Pr}(>|\mathbf{z}|)$ & odd \\
\hline $\begin{array}{c}\text { (Intercep } \\
\text { t): } 1\end{array}$ & $\begin{array}{c}1.2632 \\
0\end{array}$ & $\begin{array}{c}0.8152 \\
8\end{array}$ & $\begin{array}{c}- \\
-549\end{array}$ & 0.12128 & 0.2827483 \\
\hline
\end{tabular}

\begin{tabular}{|c|c|c|c|c|c|}
\hline $\begin{array}{c}\text { (Intercep } \\
\text { t):2 }\end{array}$ & $\begin{array}{c}1.5821 \\
1\end{array}$ & $\begin{array}{c}0.8302 \\
1\end{array}$ & $\begin{array}{c}- \\
1.906\end{array}$ & 0.05669 & 0.2055413 \\
\hline $\begin{array}{c}\text { Mom_A } \\
\text { ge }\end{array}$ & $\begin{array}{c}0.3882 \\
2\end{array}$ & $\begin{array}{c}0.1928 \\
6\end{array}$ & 2.013 & $0.04412 *$ & 1.4743551 \\
\hline $\begin{array}{c}\text { Mom_E } \\
\text { du }\end{array}$ & $\begin{array}{c}0.0231 \\
3\end{array}$ & $\begin{array}{c}0.1281 \\
1\end{array}$ & 0.181 & 0.85671 & 1.0234020 \\
\hline $\begin{array}{c}\text { Fam_ico } \\
\text { m }\end{array}$ & $\begin{array}{c}0.6238 \\
8\end{array}$ & $\begin{array}{c}0.2328 \\
0\end{array}$ & 2.680 & $\begin{array}{c}0.00736 \\
* *\end{array}$ & 1.8661608 \\
\hline $\begin{array}{c}\text { Fam_siz } \\
\text { e }\end{array}$ & $\begin{array}{c}0.2286 \\
2\end{array}$ & $\begin{array}{c}0.1823 \\
0\end{array}$ & 1.254 & 0.20979 & 1.2568689 \\
\hline Chi_Age & $\begin{array}{c}0.4927 \\
5\end{array}$ & $\begin{array}{c}0.2347 \\
8\end{array}$ & 2.099 & $0.03584 *$ & 1.6368148 \\
\hline $\begin{array}{c}\text { Chi_Bhe } \\
\text { alth }\end{array}$ & $\begin{array}{c}0.0683 \\
3\end{array}$ & $\begin{array}{c}0.1672 \\
0\end{array}$ & 0.409 & 0.68276 & 1.0707211 \\
\hline Chi_Fed & $\begin{array}{c}0.0695 \\
2\end{array}$ & $\begin{array}{c}0.2132 \\
9\end{array}$ & 0.326 & 0.74447 & 1.0719938 \\
\hline $\begin{array}{c}\text { Num_Po } \\
\text { st }\end{array}$ & $\begin{array}{c}0.9943 \\
9\end{array}$ & $\begin{array}{c}0.3393 \\
3\end{array}$ & 2.930 & $\begin{array}{c}0.00338 \\
* *\end{array}$ & 2.7030699 \\
\hline
\end{tabular}

C. Model comparison for the Proportional odd, Adjacent Categories Logit Model with Non-proportional Odds and the Forward Continuation Ratio Models

The proportional odd; the non-proportional odd adjacent categories logit and the non-proportional odd forward continuation ratio models were compared to find the best fitting model. Table $\mathrm{X}$ presents the Akaike information criteria (AIC) and the residual deviance used to compare the three models. The values of the AIC for the three models showed that the non-proportional odd adjacent categories logit model (with the least AIC) performed better than the other two models, followed by the non-proportional odds forward continuation ratio model.

Table X: Model Comparison

\begin{tabular}{|c|c|c|}
\hline Model & AIC & Residual Deviance \\
\hline Propoetiomal odd & 617.5717 & 587.5717 \\
\hline $\begin{array}{c}\text { Adjacent Categories } \\
\text { Logit Model with } \\
\text { Nonproportional Odds }\end{array}$ & 572.7221 & 516.7221 \\
\hline $\begin{array}{c}\text { Forward Continuation } \\
\text { Ratio Model with } \\
\text { Nonproportional Odds }\end{array}$ & 614.0524 & 584.0524 \\
\hline
\end{tabular}

\section{RESULTS AND DISCUSSION}

This research was undertaken to identify the main factors influencing the under-five children malnutrition in eastern part of Freetown, Sierra Leone. In line with the World Health Organization 2006, the three anthropometric indices that involve the z-score of height-for-age (stunting); weight-forheight (wasting) and weight-for-age (underweight) were used in the measurement of the dependent variable. Since malnutrition in children normally proceeds from a less alarming stage to a more alarming stage, the dependent variable was naturally ordered following these stages. Arranged in descending order of magnitude (i.e. from highly malnourish to moderately malnourish), the outcome variable, child malnutrition status was categorized as: $1=$ Very Malnourished, 2= Malnourished, 3= Moderatly malnourished. 
The ordinal regression model used in this research work is significant as the test of the full model against a model with only the intercepts was statistically significant (chi square = $84.131, \mathrm{p}<.05$ with $\mathrm{df}=15$ ). This showed that at least one of the regression coefficients in the model is not equal to zero and that the predictors as a set reliably distinguished between under-five children in the various malnutrition categories (or status).

In addition, the pseudo $\mathrm{R}^{2}$ values (e.g. Negelkerke $=0.741=74 \%$ ) presented in Table indicate that the ordinal logistic regression model with its independent variables explains relatively a good proportion of the variability in the under-five children malnutrition status.

The data were first analyzed using the baseline ordinal regression model, called the proportional odd ordinal logistic regression model. However, due to the violation of the main assumption (proportional odds or parallel line assumption) of the proportional odd model as evidenced by the Brant test, two additional ordinal regression models, the nonproportional odd adjacent category and the non- proportional odds forward continuation ratio models both of which does not depend on the proportional odd assumption were used in the analysis. At the final stage of the analysis, model comparison was made based on statistical tests. The model comparison result showed that, the non-proportional odds adjacent category model outperformed the other two ordinal regression models, followed by the non-proportional odds forward continuation ratio model.

Many factors were initially considered as potential determinants of under-five children malnutrition. However, the statistical analysis showed that, the independent variables (or factors): birth interval, mother's occupation, type of hospital, number of anti-natal hospital visits and child's birth weight were not significant determinants of under-five children malnutrition status. The results of the three ordinal regression analysis used in this work showed that: the mother's age (Mom_Age), the family income level (Fam_icom) and the number of post-natal hospital visits (Num_Post) were the main determinants of under-five children malnutrition status. In addition, based on the nonproportional odds Adjacent Categories Logit model, the child's age (Chi_Age) and the child's feeding status (Chi_Fed) were also found to be significant determinants of under-five children malnutrition status.

From the adjacent category model result contained in Table VIII, the age of the mother was found to be a significant determinant of the under-five children malnutrition status. The estimated coefficient associated with mother's age, for mothers less than 30 years (younger mothers) is positive (1.1874 ) and significant (p-value $=0.000282 * * *)$. This means that younger mothers were highly associated with high level of under-five children malnutrition.

In terms of odd ratios, the estimated odds of the under-five children being highly malnourished (versus malnourished or moderately malnourished) for the category of mothers age less than 30 years ( or younger mothers) increase by $\exp (1.1874)=3.2785$ times the odd for the category of mothers' age $\geq 30$ years. This is similar to the result obtained from the analysis of the continuation ratio model. Based on the result of the continuation ratio model, increase in the age of the mother will lead to an improvement in the nutritional status of the under-five children as it shift the malnutrition status from lower category (i.e., 1=highly malnourish) to a higher category (i.e., 2=malnourished or 3= moderately malnourished). This finding is supported by the work of [22] who observed that the high rates of teenage pregnancy contributed significantly to the high prevalence of malnutrition among under-five children

Again, from the result of the adjacent category model, the educational level of the mother is a significant determinant of the under-five children malnutrition status. The estimated coefficient associated with the category of low level of mother's education (e.g., non-formal or primary levels) is positive (0.5002) and significant (p-value=0.027946< 0.05). This means that, compared to mothers with higher (tertiary or secondary) levels of education, mothers with lower level of education (non-formal or primary levels) are associated with higher level of under-five children's malnutrition. In terms of odd ratios, the odds of the underfive children being very malnourished versus malnourished or moderately malnourished for the category of less educated (non-formal or primary) mothers increase by $\exp (0.5002)$ $=1.649$ times the odds for educated or highly educated mothers.

On the other hand, the estimated coefficient associated with secondary or tertiary levels ( high level) of education is negative (-0.4827). This means that, the higher the level of the mothers' education, the lower the malnutrition status of the under five children. In terms of odd ratios, the estimated odds of the under-five children being very malnourished versus malnourished or moderately malnourished for the category of under-five children from the educated or highly educated mothers reduced by $\exp (-0.4827)=0.617$ times the odd for the category of non-educated (or low educated) mothers. Reference [15] also found a positive relationship between mothers' years of primary education and stunting. In particular, they found that, mothers' years of post-primary education were significantly inversely related to stunting

In terms of family income, the estimated coefficient associated with low level family income is positive and significant ( $\mathrm{p}$-value $=0.027946<0.05$ ). This means that, low income category of family income can lead to an increase in the malnutrition status of the under-five children. In terms of odd ratios, the odds of the under-five children being very malnourish versus malnourish or moderately malnourish for the category of low level income families increase by $\exp (0.1273)=1.1357$ times the odds for middle or high level income families. This result is supported by some other 
researchers ((e.g., [20]) who discover an inverse relationship between maternal education and child malnutrition.

Also, given the family income level, the estimated coefficient associated with high level family income is negative and significant ( $\mathrm{p}$-value $=0.005754 * *$ ) This means that, high level income category of family income can lead to a decrease in the malnutrition status of the under-five children. In terms of odds ratios, the odds of the under-five children being very malnourish versus malnourish or moderately malnourish for the category of high (or middle) level income families decrease by $\exp (-1.0580)=$ times the odds for the category of low level income families. The result of the continuation ratio model also showed that, increase in family income will shift the malnutrition status from the highly malnourished category (i.e. lower category 1 ) to a category beyond. That is, to the malnourished category or the moderately malnourished category (or category 2 or 3 ), This is consistent with the findings of Amare, et al who discovered that children from well to do families were less likely to be stunted compared to children from the poor or less privileged homes.

The size of the family was another significant determinant of under-five children malnutrition status. The estimated coefficient associated with small family size is negative. This means that, small family size can lead to a decrease in the malnutrition status of the under-five children. In terms of odd ratios, the odds of the under-five children being very malnourish versus malnourish or moderately malnourish for small (or normal) family size decrease by $\exp (-0.8852)$ $=0.41263$ times the odds for the category of large family size. This is supported by the work of [23] who discovered that Children from larger households are significantly shorter and consume diets of poorer quality, as assessed by intake of foods from animal sources.

The age of the child was another significant factor that may influence the under-five children malnutrition status. The estimated coefficient associated with the age of the child is positive (1.1793). This means that increase in child's age will lead to an increase in the malnutrition status of the under-five children. In terms of odd ratios, the odds of the under-five children being very malnourish versus malnourish or moderately malnourish for older children increase by $\exp (1.1793)=3.2520$ times the odds for the category of younger children. This agrees with the findings of [12], who discovered that in comparison with children less than 6 months, children aged 6-23 months and 24-59 months had higher odds of being stunted

The child feeding status (Chi_Fed:1) was also found to be a significant determinant of the under-five children malnutrition status. The estimated coefficient associated with the child's feeding status is negative. This means that, the higher the feeding status (in terms of quality and frequency), the lower the malnutrition status of the under-five children

In terms of odd ratios, the odds of the under-five children being very malnourished versus malnourished or moderately malnourished for high feeding status decrease by $\exp (-$ $1.2019)=0.3006$ times the odds for the category of under-five children with low feeding status. This finding agrees with the result obtained by [2] which pointed out that a very good nutrition during the first 1000 days between conception and a child's second birthday is important for children to reach their full growth and development potentials.

Above all, the frequency of postnatal hospital visits was found to be a significant determinant of under-five children malnutrition status, the estimated coefficient associated with a low post-natal hospital visit (Not regular or never visited the hospital) is positive. That is, low post-natal hospital visit category is linked with high level of malnutrition status. In terms of odds ratios, the odds of less (or zero) number of postnatal hospital visit increased the malnutrition status by $\exp (1.5743)=4.827$ times the estimated odd of the high category of postnatal hospital visit. This is not surprising because, low postnatal hospital visit can lead to poor health status. This view is also supported by [21] and [24], who in their research findings discovered that repeated attacks of diarrhea and infectious disease can lead to a weight loss and can therefore influence the child's nutritional status.

The more frequent the number of post-natal hospital visit, the less severe the malnutrition status of the under-five children

\section{CONCLUSION}

The main purpose of this research was to identify the main factors influencing the malnutrition status of the under-five children living in the eastern part of Freetown, Sierra Leone. Since malnutrition in children normally proceeds from a less alarming stage to a more alarming stage, the dependent variable was naturally ordered following these stages. Based on the ordinal nature of the dependent variable, three ordinal regression models, the proportional odds; the non-proportional odds adjacent categories and the non-proportional odds forward continuation ratio logit models were used in the analysis. Model comparison was made based on statistical tests. The model comparison result showed that, the nonproportional odds adjacent category model outperformed the other two ordinal regression models, followed by the nonproportional odds forward continuation ratio model.

Above all, the empirical analysis showed that: the mother's age (Mom_Age), the family income level (Fam_icom) and the number of post-natal hospital visits (Num_Post) were the main factors influencing the under-five children malnutrition status. Also, the age and the feeding status of the child were somehow found to be statistically significant contributors to the under-five children malnutrition status. Compared to the malnutrition status of under-five children from older mothers, the malnutrition status of under-five children from younger mothers was high. That is, under-five children from younger mothers were more malnourish than those from older mothers. The more frequent the number of post-natal hospital visit, the less severe the malnutrition status of the under-five children. Similarly, increase in family income will reduce the 
incidence of malnutrition in under-five children. Also, malnutrition increases in older children as compared to younger children. Finally, the higher the quality and frequency of child feed, the lower the incidence of malnutrition in under-five children.

\section{RECOMMENDATION:}

Based on the result of the present research work, the following recommendations were made in order

to avoid or minimize the: incidence of under-five children malnutrition in the study area and in Sierra Leone as a whole ;

$>$ The Government of Sierra Leone should strengthen community health workers' capacities by integrating more child care strategies into the national preservice curricula for primary health care providers including community health workers.

$>$ The Government should also provide and monitor supplies of life-saving nutritional foods that include therapeutic foods that are ready-to-use to remote communities with acute under-five children malnutrition.

$>$ In addition, Breast feeding is highly recommended especially for children born from low income families. Reference [26] also stressed the nutritional significant of breastfeeding as a means of prevention of various types of childhood malnutrition and micronutrient deficiencies

\section{REFERENCE}

[1] Abuya BA, Onsomu EO, Kimani JK, Moore D (2011): Influence of Maternal Education on Child Immunization and Stunting in Kenya. Matern Child Health J. 2011, 15: 1389-1399. 10.1007/s10995-010-0670-z

[2] Adair LS, Fall CH, Osmond C, Stein AD, Martorell R, RamirezZea M, Sachdev HS, Dahly DL, Bas I, Norris S, Micklesfield L, Hallal P, Victora C, (2013) for the COHORTS Group Associations of linear growth and relative weight gain during early life with adult health and human capital in countries of low and middle income: findings from five birthcohort studies. The Lancet. 2013;382(9891):525-34.

[3] ADB (2001). Improving Children Nutrition in Asia. Nutrition and Development Series No. 3. Manila

[4] Agresti Alan .(2007). An Introduction to Categorical Data Analysis (Second Edition). John Wiley \& Sons, Inc. Canada

[5] Ananth, C. V. and Kleinbaum, D. G. (1997). Regression models for ordinal responses: A review of methods and applications. International Journal of Epidemiology 26, 1323-1333.

[6] Armstrong, B. B. \& Sloan, M. (1989). Ordinal regression models for epidemiological data. American Journal of Epidemiology, 129(1), 191-204.

[7] Fienberg, S. E. (1980). The analysis of cross-classified categorical data. Cambridge, MA: The MIT Press

[8] Frost MB, Forst R, Hass DW: Maternal education and child nutritional status in Bolivia the links. SocSci Med. 2005, 60 (2):395-407. 10.1016/j.socscimed.2004.05.010.
[9] Black R.E., Victora C.G., Walker S.P., Bhutta Z.A., Christian P., de Onis M., Ezzati M., Grantham-McGregor S., Katz J., Martorell R., et al. Maternal and child undernutrition and overweight in lowincome and middle-income countries. Lancet. 2013;382:427-451. doi: 10.1016/S0140-6736(13)60937-X

[10] Fienberg, S. E. (1980). The analysis of cross-classified categorical data. Cambridge, MA: The MIT Press.

[11] Greenwood, J., Hercowitz, Z., Hu!man, G., 1988. Investment, capacity utilization, and the real business cycle. American Economic Review 78, 402$\} 417$.

[12] Hall J, Walton M, Van Ogtrop F, et al, (2020) Factors influencing undernutrition among children under 5 years from cocoa-growing communities in Bougainville BMJ Global Health 2020;5:e02478.

[13] Hardin, J. W., \& Hilbe, J. M. (2007). Generalized linear models and extensions (2nd ed.). Texas: Stata Press.

[14] Hosmer, D. W. and Lemeshow, S., Applied Logistic Regression (2th edn). Wiley, New York, 2000.

[15] Kabubo-Mariara, J., G.K. Ndenge, and D.K. Mwabu. (2009). "Determinants of Children's Nutritional Status in Kenya: Evidence from Demographic and Health Surveys." Journal of African Economies 18(3): 363-87

[16] Long, J. S. \& Freese, J. (2006). Regression models for categorical dependent variables using Stata (2nd ed.). Texas: Stata Press.

[17] Long, J. S., \& Freese, J. (2014). Regression models for categorical dependent variables using Stata (3rd edition). College Station, TX: Stata Press

[18] Martins, V. J. B., Toldeo Florencio, T. M. M., Grillo, L. P., Franco, M. D. C. P., Martins, P. A., Clemente, A. P. G., Santos, C. D. L., Vieira, M. de F. A. and Sawaya, A. L. (2011) 'Long-lasting effects of undernutrition'. International Journal of Environmental Research and Public Health 8(6): 1817-46.

[19] McCullagh, P. \& Nelder, J. A. (1989). Generalized linear models (2nd ed.). London: Chapman and Hall.

[20] Mukuria, A., J. Cushing, and J. Sangha. 2005. Nutritional Status of Children: Results from the Demographic and Health Surveys 1994-2001. DHS Comparative Report No. 10. Calverton, MD, USA: ORC Macro.

[21] Muller O, Krawinkel M. Malnutrition and health in developing countries. CMAJ. 2005;173(3):279-286. doi: 10.1503/cmaj.050342.

[22] Olodu MD, Adeyemi AG, Olowookere SA, Esimai OA. Nutritional status of under - five children born to teenage mothers in an urban setting, south - western Nigeria. BMC Res Notes. 2019:1-6.

[23] Pelto G.H. \& Armar-Klemesu M. (2013) Feeding Infants and Young Children in Vihiga County, Western Kenya: Report from a Focused Ethnographic Study. GAIN: Geneva

[24] Santosh Kumar A, Sunil Kumar D, Ashok NC, (2013). Ragavendraswamy Koppad R. Protein energy malnutrition and its association with immunization status and common morbidities among 1-5 year aged children in southern part of India, Mysore. Int J Curr Res Rev. 2013;5(2):105-110.

[25] Scherbaum V, Srour ML. (2016) The Role of Breastfeeding in the Prevention of Childhood Malnutrition. World Rev Nutr Diet. 2016;115:82-97. doi: 10.1159/000442075. Epub 2016 May 19. PMID: 27198529.

[26] Wemakor, A., Garti, H., Azongo, T. et al. (2018).Young maternal age is a risk factor for child undernutrition in Tamale Metropolis, Ghana. BMC Res Notes 11,877 (2018).https://doi.org/10.1186/s13104-018-3980-7

[27] WHO Multicentre Growth Reference Study Group (2006). Reliability of anthropometric measurements in the WHO Multicentre Growth Reference Study. Acta Paediatrica, Suppl 450:39-47 